\title{
The Forefront for Novel Therapeutic Agents Based on the Pathophysiology of Lower Urinary Tract Dysfunction: Pathophysiology and Pharmacotherapy of Overactive Bladder
}

\author{
Masaki Yoshida ${ }^{1, *}$, Koichi Masunaga ${ }^{2}$, Takashi Nagata ${ }^{3}$, Makoto Yono $^{4}$, and Yukio Homma \\ ${ }^{\prime}$ Department of Urology, Kumamoto Hospital of Japan Labor Health and Welfare Organization, \\ 1670 Takehara-cho, Yatsushiro-city, Kumamoto 866-8533, Japan \\ ${ }^{2}$ Department of Urology, Tokyo Metropolitan Geriatric Hospital, 3-2 Sakae-cho, Itabashi-ku, Tokyo 173-0015, Japan \\ ${ }^{3}$ Department of Urology, Toshiba Hospital, 6-3-22 Higashi-ohi, Shinagawa-ku, Tokyo 140-8522, Japan \\ ${ }^{4}$ Department of Urology, Graduate School of Medical Sciences, Kumamoto University, \\ 1-1-1 Honjo, Kumamoto 860-8556, Japan \\ ${ }^{5}$ Department of Urology, Graduate School of Medicine, The University of Tokyo, \\ 7-3-1 Hongo, Bunkyo-ku, Tokyo 113-8655, Japan
}

Received August 2, 2009; Accepted August 31, 2009

\begin{abstract}
Overactive bladder (OAB) syndrome, which is characterized by a complex of storage symptoms (urinary urgency, frequency, nocturia, and urgency incontinence) is highly prevalent within the general population, causing major distress to patients in terms of their psychosocial and physical functioning. Muscarinic receptors of bladder smooth muscles are involved in both normal and disturbed bladder contraction. The muscarinic receptor functions may change in bladder disorders associated with $\mathrm{OAB}$, implying that mechanisms, which normally have little clinical importance, may be up-regulated and contribute to the pathophysiology of OAB. In addition, several reports have suggested that various stimulations release many substances, including adenosine triphosphate, prostaglandins, nitric oxide, and acetylcholine, from bladder urothelium, which contribute to pathophysiology of the increased bladder sensation, OAB symptoms, and detrusor overactivity. Bladder urothelium possesses a non-neuronal cholinergic system and high density of muscarinic receptors. The roles and functions of the non-neuronal cholinergic system in $\mathrm{OAB}$ are now being evaluated. In the pharmacotherapy of $\mathrm{OAB}$, antimuscarinic agents are the first choice drugs. Furthermore, new therapeutic targets at the levels of the urothelium, detrusor muscles, autonomic and afferent pathways, spinal cord, and brain are proposed. In this review, the pathophysiology of $\mathrm{OAB}$, especially the role of non-neuronal acetylcholine, is discussed. In addition, new drugs with new action mechanisms will be introduced.
\end{abstract}

Keywords: overactive bladder, pathophysiology, pharmacotherapy, antimuscarinic drug, muscarinic receptor, lower urinary tract

\section{Definition and prevalence of overactive bladder (OAB)}

$\mathrm{OAB}$ is a symptom complex that is comprised of the storage symptoms of urgency with or without urgency incontinence, frequency, and nocturia (1). These symp-

*Corresponding author. akko-maki@umin.net Published online in J-STAGE on February 4, 2010 (in advance) doi: 10.1254/jphs.09R12FM toms are suggestive but not diagnostic of detrusor overactivity (urodynamically demonstrable involuntary bladder contractions) if there is no proven infection or other obvious pathology. OAB is, therefore, clearly distinct from urodynamically proven detrusor overactivity, although the majority of people with $\mathrm{OAB}$ are thought to have this underlying diagnosis. The prevalence of $\mathrm{OAB}$ increases with age. From the epidemiological studies conducted to date, it can be concluded that of those patients with $\mathrm{OAB}$, approximately one-third are troubled 
by incontinence (OAB 'wet') and two-thirds are not (OAB 'dry') $(2,3)$. The NOBLE (National Overactive Bladder Evaluation) study (3) estimated the overall prevalence of this condition in the US population to be $16 \%$ in men and $16.9 \%$ in women. As the population ages, an overall increase in prevalence occurs. A Japanese epidemiological survey (4) estimated a slightly lower overall incidence (12.4\%) in the general population aged over 40 , but the prevalence increased with age, with more than $20 \%$ of people older than 70 years and more than $35 \%$ older than 80 suffering lower urinary tract symptoms.

More recent data from the EPIC (European Prospective Investigation into Cancer and Nutrition) Study suggest that the prevalence of OAB symptoms [using the 2002 International Continence Society (ICS) definition] is closer to $12 \%$ in the community; and of these sufferers, approximately $50 \%$ experience significant bother from their symptoms (5).

\section{Pathophysiology of OAB}

\subsection{Increased myogenic activity of detrusor smooth muscles}

This is an important mechanism inducing $\mathrm{OAB}$ and detrusor overactivity, which seems to be more applicable to patients with bladder outlet obstruction (BOO). Partial $\mathrm{BOO}$ increases intravesical pressure and induces bladder hypertrophy and partial denervation of the bladder smooth muscle, leading to various functional changes in smooth muscles. These changes include denervation supersensitivity of cholinergic (muscarinic) receptors (6), increases in purinergic receptor-mediated contractile responses as well as expression of purinergic receptors such as $\mathrm{P}_{2} \mathrm{X}_{1}(7,8)$, and changes in the cell-to-cell communication in detrusor muscles due to up-regulation of gap-junction proteins such as connexin $43(9,10)$. Thus, increases in receptor-mediated muscle contractility and interaction between smooth muscles cells can result in coordinated myogenic contraction of the entire bladder and detrusor overactivity.

It has been suggested that local contraction (activity) that occurs somewhere in the detrusor will spread throughout the bladder wall, resulting in coordinated myogenic contraction of the whole bladder. This local contraction in the bladder wall has been shown to generate afferent discharge (11). Recently, localized bladder activity was assessed by the micromotion detection method, demonstrating that women with increased bladder sensation on filling cystometry had a significantly higher prevalence of localized activity than the control group (12). This observation suggests that localized distortion of the bladder wall simulates afferent activity, which would precipitate a feeling of urgency and detrusor overactivity.

In addition, another population of cells in the bladder known as interstitial cells has been proposed for a pacemaking role in spontaneous activity of the bladder (13, 14). Because it has been reported that the number of interstitial cells is increased in a guinea-pig model of BOO (15) and that c-kit tyrosine kinase inhibitors, which inhibit interstitial cell activity, decreased the amplitude of spontaneous contractions in the guinea-pig and human bladder $(16,17)$, interstitial cells may also be involved in the emergence of detrusor overactivity because of enhanced autonomous detrusor muscle activity.

\subsection{Role of urothelium and bladder afferent}

The bladder urothelium has roles other than just being a barrier. There is increasing evidence that urothelial cells play an important role in modulation of bladder activity by responding to local chemical and mechanical stimuli and then sending chemical signals to bladder afferent nerves. It has been shown that urothelial cells express various "sensor molecules" such as receptors of bradykinin, neurotrophins, purines (P2X and P2Y), norepinephrine (NE) ( $\alpha$ and $\beta$ ), ACh (nicotinic and muscarinic), epithelial $\mathrm{Na}^{+}$channels $(\mathrm{ENaC})$, and a number of transient receptor potential (TRP) channels. These sensor molecules respond to mechanical as well as chemical stimuli and in turn release chemicals such as ATP, prostaglandins (PG), nerve growth factor (NGF), ACh,

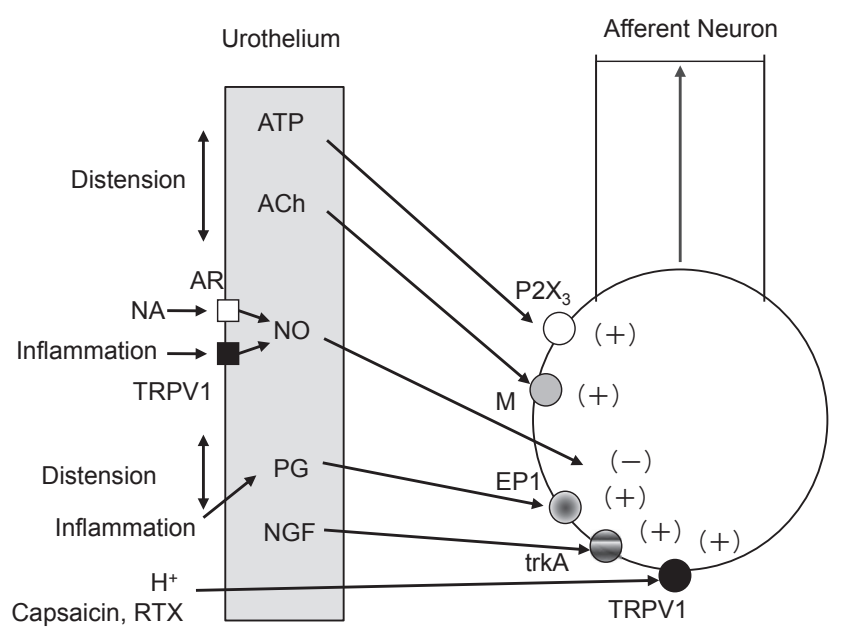

Fig. 1. Bladder urothelial mechanico-afferent transduction. Urothelium releases many neurotransmitters and factors due to bladder distension or various stimulations. These factors contribute to the stimulation and inhibition of afferent $\mathrm{C}$ neurons, suggesting the important role in the symptoms of OAB. ATP: adenosine triphosphate, $\mathrm{ACh}$ : acetylcholine, NA: noradrenaline, AR: adrenergic receptor, NO: nitric oxide, PG: prostaglandin, RTX: resiniferatoxin, M: muscarinic receptor, NGF: nerve growth factor. 
and NO. These agents are known to have excitatory or inhibitory actions on afferent nerves, which are located close to or in the urothelium (Fig. 1).

Neural plasticity of bladder afferent pathways is also one of the mechanisms of OAB. Urothelial dysfunction that can increase the amount of urothelially released substances may lead to the changes in properties of bladder afferent pathways, resulting in increased $O A B$ symptoms. In particular, C-fiber bladder afferents may be critical for symptom generation in pathologic states such as OAB because these fibers demonstrate remarkable plasticity: After neurologic or possibly inflammatory insult, $\mathrm{C}$-fibers become the predominant afferent route carrying impulses involved in the micturition reflex to the spinal tract $(18,19)$.

\subsection{Urothelial alterations in $O A B$}

Several specific alterations in urothelial function and ultrastructure have been demonstrated in OAB. Expression of the mechanosensitive $\mathrm{ENaC}$ is increased significantly in human obstructed bladders in comparison with unobstructed controls and correlates significantly with storage symptom scores (20). It is possible that increased expression of mechano-sensitive channels such as $\mathrm{ENaC}$ in the urothelium enhances substance release upon bladder stretch. In accordance, stretch-evoked ATP release from urothelial cells is enhanced in chronic spinal cordinjured animal models (21). Release of ACh from human urothelial and suburothelial sites increases with age, as well as during bladder stretch, and represents a functional, non-neuronal, alternative cholinergic system (22). Levels of PG, which are locally synthesized in bladder muscle and mucosa, and levels of NGF are increased in subjects with $\mathrm{OAB}$ in comparison with controls; and in symptomatic patients, levels of $\mathrm{PGE}_{2}$ are positively correlated with voiding behavior and maximum cystometric capacity $(23,24)$.

Overall, up-regulation of urothelial function and increased release of various chemical mediators and known neurotransmitters may influence afferent nerve activity to generate $\mathrm{OAB}$ symptoms, although the precise mechanism by which these processes interact with neural tissue to achieve signal transduction remains to be clarified.

\subsection{Role of non-neuronal $\mathrm{ACh}$ and the muscarinic receptors}

Previously, we demonstrated that non-neuronal ACh release increased and was significantly greater in stretched human bladder strips with intact urothelium, when compared with those without urothelium (22). The release was also related to age of the bladder tissue donor.

In addition, non-neuronal ACh releases were gradually

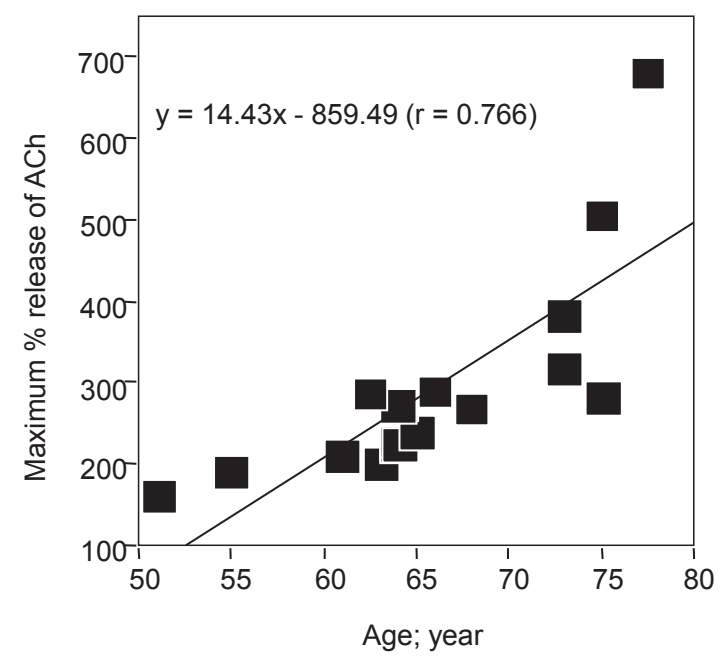

Fig. 2. Effect of age on stretch-induced non-neuronal ACh release from human bladder strip with urothelium. Correlation between age and stretch-induced maximal percentage of release of non-nerveevoked ACh. For measurement of non-nerve-evoked ACh, microdialysis procedure was performed in all bladder strips pretreated with tetrodotoxin $(1 \mu \mathrm{M})$, under $0-\mathrm{mN}$ resting tension. (Reproduced from Ref. 22 with permission)

increased according to the elevation of the resting tension by stretch of bladder strips with urothelium, and the releases were increased age-dependently (Fig. 2). It is supposed that the elevation of the resting tension of bladder strips is a similar condition to distension of bladder wall in the storage phase of the micturition cycle. Thus, it may be assumed that during the storage phase, there is an ongoing stimulation of detrusor tone by ACh released from non-neuronal sources, possibly the urothelium.

Although the exact action mechanism of non-neuronal $\mathrm{ACh}$ for the bladder function has not been elucidated, the muscarinic receptors-mediated mechanism in afferent neurons, myofibroblast, and urothelium might be related. For the targets of non-neuronal ACh from the urothelium, it could be expected to enhance the muscarinic receptorsmediated myogenic contractile activity of the detrusor, which has been proposed to be increased in patients with detrusor overactivity. The increased myogenic activity may, in turn, increase firing in afferent nerves and contribute to symptoms of OAB. It is also possible that non-neuronal $\mathrm{ACh}$ acts on afferent nerves to initiate the micturition reflex. Currently, no evidence has shown that such receptors are present on the terminals of afferents that supply the bladder. Hawthorn et al. (25) reported 1.5 times greater numbers of muscarinic receptors in the urothelium than in the smooth muscle layer in the pig bladder. A recent report (26) also demonstrated a high density of $\mathrm{M}_{2}$ muscarinic receptors in the human bladder mucosa. Furthermore, Mukerji et al. (27) reported that $\mathrm{M}_{2}$ and $\mathrm{M}_{3}$ immunoreactive staining presented in human 
detrusor, myofibroblast-like cells, nerve fiber bundle, and dorsal root ganglion of small and medium sensory neurons in the suburothelium. These muscarinic receptors might be targets of non-neuronal ACh from the urothelium.

Recently, to clarify the contribution of mucosal muscarinic receptors to bladder function, we investigated the effects of various antimuscarinic drugs on the stretchinduced non-neuronal ATP release in human bladder (28). In this study, non-neuronal ATP release from bladder strip without mucosa was about $10 \%$ of that from strip with mucosa. Non-neuronal ATP release was significantly inhibited by pretreatment with nifedipine or in $\mathrm{Ca}^{2+}$-free medium. Both methoctramine $\left(\mathrm{M}_{2}\right.$ receptorselective antagonist $)$ and 4-DAMP $\left(\mathrm{M}_{3}\right.$ receptor-selective antagonist) significantly inhibited the release. However, an $\mathrm{M}_{1}$ receptor-selective antagonist (pirenzepine) did not have significant effect on the release (Fig. 3A). Oxybutynin, propiverine, tolterodine, and solifenacin caused concentration-dependent inhibition in non-neuronal ATP release. The rank order of the maximum inhibition rate was propiverine $\geq$ solifenacin $\geq$ tolterodine $\geq$ oxybutynin. Solifenacin showed the inhibitory effect at lower concentration, as compared to the other drugs (Fig. 3B). The data suggest that human bladder mucosa is a main source of stretch-induced non-neuronal ATP release and that stimulation of $\mathrm{M}_{2}$ - and $\mathrm{M}_{3}$-receptor subtypes of mucosa partly contributes to non-neuronal ATP release. Various antimuscarinic drugs used for $\mathrm{OAB}$ treatment may have different inhibitory effects on non-neuronal ATP release.

Muscarinic receptors are involved in both normal and disturbed contraction, and the most common drug treatment for $\mathrm{OAB}$ is antimuscarinic drugs. It is reported that antimuscarinic drugs act mainly during the storage phase, increasing bladder capacity and decreasing urgency, while there is normally no activity in parasympathetic nerves during the storage phase (29). However, if there is an increased non-neuronal $\mathrm{ACh}$ release during storage, which is proposed to be a contributing factor to $\mathrm{OAB}$, it is possible that antimuscarinic drugs have some inhibitory effects on muscarinic receptors activated by the non-neuronal $\mathrm{ACh}$. In addition, it will be speculated that non-neuronal ACh may stimulate muscarinic receptors on mucosa and cause the release of non-neuronal ATP in human bladder. One of the action mechanisms of antimuscarinic drugs might be the inhibitory effect on mucosal muscarinic receptors, resulting in inhibition of non-neuronal ATP release. Thus, these data may provide useful information about the action mechanism of antimuscarinic drugs during the storage phase.
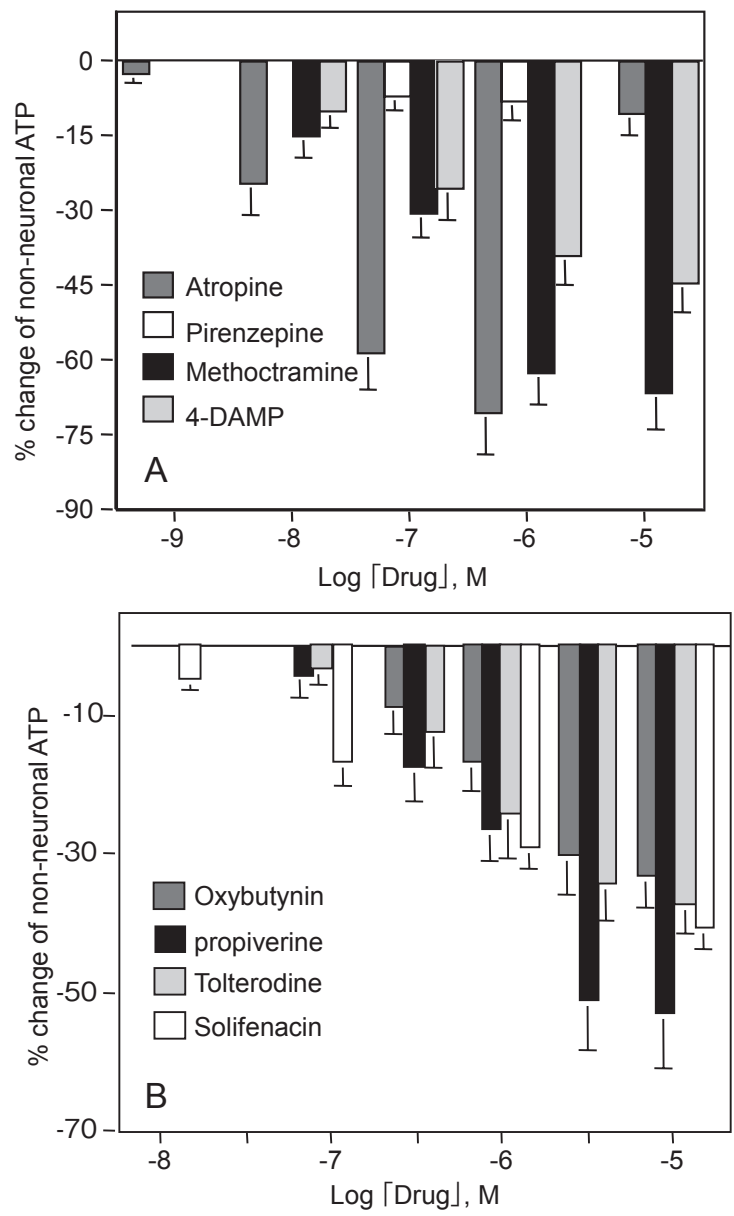

Fig. 3. Effects of antimuscarinic agents on non-neuronal ATP release from human bladder. A: Concentration-dependent inhibitions of muscarinic receptor selective antagonists of non-neuronal ATP release from human bladder strip with mucosa. Atropine $(0.001$, $0.01-1.0 \mu \mathrm{M}: \mathrm{n}=8)$, pirenzepine $(0.01-10 \mu \mathrm{M}: \mathrm{n}=8)$, methoctramine $(0.01-10 \mu \mathrm{M}: \mathrm{n}=8)$ and 4-DAMP $(0.01-10 \mu \mathrm{M}: \mathrm{n}=8)$. $\mathrm{B}$ : Concentration-dependent inhibitions of various antimuscarinic agents on non-neuronal ATP releases from strips with mucosa. Oxybutynin $(0.01,0.1,0.3,1,3$, and $10 \mu \mathrm{M}: \mathrm{n}=8)$, propiverine $(0.01,0.1$, $0.3,1,3$, and $10 \mu \mathrm{M}: \mathrm{n}=8$; tolterodine $(0.01,0.1,0.3,1,3$, and 10 $\mu \mathrm{M}: \mathrm{n}=8)$, and solifenacin $(0.01,0.1,1$, and $10 \mu \mathrm{M}: \mathrm{n}=8)$. For measurement of non-neuronal ATP, microdialysis procedure was performed in all bladder strips pretreated with tetrodotoxin $(1 \mu \mathrm{M})$, and $40 \mathrm{mN}$ resting tension. (Reproduced from Ref. 28 with permission)

\section{Pharmacotherapy}

There are a number of pharmacological mechanisms that could reduce overactivity of the detrusor muscle. However, the only approved treatments with Grade A recommendation based on level 1 evidence are antimuscarinic drugs (30). An extensive literature base has demonstrated acceptable efficacy, safety, and improvements in quality of life in randomized controlled trials 
for the antimuscarinic drugs (tolterodine, trospium, solifenacin, and darifenacin), drugs with mixed actions (oxybutynin and propiverine), and the vasopressin analogue desmopressin (for nocturia) (31). However, muscarinic receptors are not exclusively found in the urinary tract, but are also present in salivary glands (muscarinic $\mathrm{M}_{1}$ - and $\mathrm{M}_{3}$-receptor subtypes), gastrointestinal smooth muscle (muscarinic $\mathrm{M}_{2}$ - and $\mathrm{M}_{3}$-receptor subtypes), eyes (muscarinic $\mathrm{M}_{3}$ - and $\mathrm{M}_{5}$-receptor subtypes), heart (muscarinic $\mathrm{M}_{2}$-receptor subtype), and brain (muscarinic $\mathrm{M}_{1^{-}}$, $\mathrm{M}_{3^{-}}, \mathrm{M}_{4^{-}}$, and $\mathrm{M}_{5}$-receptor subtypes). This widespread distribution of muscarinic receptors within the body is related to the commonly observed side-effects of these agents, including dry mouth, constipation, blurred vision, tachycardia, and cognitive problems (31). To avoid these side effects, the development of new therapeutic drugs is ongoing.

Potassium-channel openers have failed to show any efficacy (32). Aprepitant, an NK-1-receptor antagonist used for treatment of chemotherapy-induced nausea and vomiting (33) significantly improved symptoms of OAB in postmenopausal women with a history of urgency incontinence or mixed incontinence (with predominantly urgency urinary incontinence), as shown in a well-designed pilot randomized controlled trials (34).

The effective alternative class of agents to the antimuscarinics with proven efficacy and acceptable tolerability are the $\beta_{3}$-adrenoceptor agonists (35). The detrusor muscle containing $\beta$-ARs and three subtypes $\left(\beta_{1}, \beta_{2}\right.$, and $\beta_{3}$ ) have been identified in most species $(36,37)$. The human urothelium also contains all three receptor subtypes (38). Studies using real-time RT-PCR have revealed a predominant expression of $\beta_{3}$-AR mRNA in human detrusor muscle $(37,39)$, and the functional evidence for an important role in both normal and neurogenic bladders is convincing $(37,40-47)$. A number of $\beta_{3}$-AR-selective agonists, including GW427353, YM178, and KUC7483, are currently being evaluated as a potential treatment for $\mathrm{OAB}$ in humans (48).

Vanilloid receptor agonists capsaicin and resiniferatoxin have proven efficacy but are associated with adverse events such as urinary retention, limiting their more widespread applicability (49). Botulinum toxin A, although not approved for use in $\mathrm{OAB}$ and detrusor overactivity in most countries, has a well-documented therapeutic effect in neurogenic detrusor overactivity, and it may also be useful for idiopathic detrusor overactivity. It has largely replaced the vanilloids as therapeutic alternatives. However, there are not data from large-scale randomized controlled trials. It has an associated urinary retention rate and suffers an absence of long-term data associated with its use (50).

Future promising drugs for $\mathrm{OAB}$ include phospho- diesterase inhibitors, gonadotropine-releasing-hormone antagonists, vitamin D3-receptor analogues, EP-1-receptor antagonists, TRPV1-receptor antagonists, drugs with central mode of action (gabapentin: one of the new first-generation antiepileptic drugs, etc.) (51).

\section{Conclusions}

The pathophysiology of $\mathrm{OAB}$ is multifactorial. Recently, many evidences suggested the important role of urothelium in the mechanism of $\mathrm{OAB}$ and detrusor overactivity. Although antimuscarinic drugs are still the mainstay for treatment of $\mathrm{OAB}$, development of several drugs with different mechanisms will be promising in the near future.

\section{References}

1 Abrams P, Cardozo L, Fall M, Griffiths D, Rosier P, Ulmsten U, et al. The standardization of terminology of lower urinary tract function: report from the standadisation sub-committee of international continence society. Neurourol Urodyn. 2002;21: 167-178.

2 Milsom I, Abrams P, Cardozo L, Roberts RG, Thuroff J, Wein AJ. How widespread are the symptoms of an overactive bladder and how are they managed? A population-based prevalence study. BJU Int. 2001;87:760-766.

3 Stewart WF, Van Rooyen JB, Cundiff GW, Abram P, Herzog A, Corey R, et al. Prevalence and burden of overactive bladder in the United States. World J Urol. 2003;20:327-336.

4 Homma Y, Kakizaki H, Gotoh M, Takei M, Yamanishi T, Hayashi K. The Members of Committee. [Epidemiologic survey on lower urinary tract symptoms in Japan.] J Neurogenic Bladder Soc. 2003;14:266-277. (in Japanese)

5 Irwin DE, Milsom I, Hunskaar S, Reilly K, Kopp Z, Herschorn $S$, et al. Population-based survey of urinary incontinence, overactive bladder, and other lower urinary tract symptoms in five countries: results of the EPIC study. Eur Urol. 2006;50: 1306-1315.

6 Speakman MJ, Brading AF, Gilpin CJ, Dixon JS, Gilpin SA, Gosling JA. Bladder outflow obstruction - a cause of denervation supersensitivity. J Urol. 1987;138:1461-1466.

7 Boselli C, Govoni S, Condino AM, D'Agostino G. Bladder instability: a re-appraisal of classical experimental approaches and development of new therapeutic strategies. J Auton Pharmacol. 2001;21:219-229.

8 O'Reilly BA, Kosaka AH, Chang TK, Ford AO, Popert R, McMahon SB. A quantitative analysis of purinoceptor expression in the bladders of patients with symptomatic outlet obstruction. BJU Int. 2001;87:617-622.

9 Christ GJ, Day NS, Day M, Zhao W, Persson K, Pandita RK, et al. Increased connexin43-mediated intercellular communication in a rat model of bladder overactivity in vivo. Am J Physiol Regul Integr Comp Physiol. 2003;284:R1241-R1248.

10 Haferkamp A, Mundhenk J, Bastian PJ, Reitz A, Dorsam J, Pannek J, et al. Increased expression of connexin 43 in the overactive neurogenic detrusor. Eur Urol. 2004;46:799-805.

11 Downie JW, Armour JA. Mechanoreceptor afferent activity 
compared with receptor field dimensions and pressure changes in feline urinary bladder. Can J Physiol Pharmacol. 1992;70: $1457-1467$.

12 Drake MJ, Harvey IJ, Gillespie JI, Van Duyl WA. Localized contractions in the normal human bladder and in urinary urgency. BJU Int. 2005;95:1002-1005.

13 Andersson KE, Arner A. Urinary bladder contraction and relaxation: physiology and pathophysiology. Physiol Rev. 2004;84: 935-986.

14 Yoshimura N, Chancellor MB. Physiology and pharmacology of the bladder and urethra. In: Wein AJ, editor. Campbell-Walsh urology. Vol. 3, 9th ed, Section XIV, Chapter 56. Philadelphia, PA: Saunders; 2007. p. 1922-1972.

15 Kubota Y, Kojima Y, Hayase M, Hirose M, Okada O, Sasaki S, et al. Association between bladder overactivity and increased numbers of interstitial cells in the guinea pigs with partial bladder outlet obstruction. J Urol. 2007;177 4 Suppl:85 (abstract).

16 Biers SM, Reynard JM, Doore T, Brading AF. The functional effects of a c-kit tyrosine inhibitor on guinea-pig and human detrusor. BJU Int. 2006;97:612-616.

17 Kubota Y, Biers SM, Kohri K, Brading AF. Effects of imatinib mesylate (Glivec) as a c-kit tyrosine kinase inhibitor in the guinea-pig urinary bladder. Neurourol Urodyn. 2006;25:205-210.

18 Ouslander JG. Management of overactive bladder. N Engl J Med. 2004;350:786-799.

19 Yoshimura N, Chancellor MB. Current and future pharmacological treatment for overactive bladder. J Urol. 2002;168: 1897-1913.

20 Araki I, Du S, Kamiyama M, Mikami Y, Matsushita K, Komuro $\mathrm{M}$, et al. Overexpression of epithelial sodium channels in epithelium of human urinary bladder with outlet obstruction. Urology. 2004;64:1255-1260.

21 Khera M, Somogyi GT, Kiss S, Boone TB, Smith CP. Botulinum toxin A inhibits ATP release from bladder urothelium after chronic spinal cord injury. Neurochem Int. 2004;45:987-993.

22 Yoshida M, Inadome A, Maeda Y, Satoji Y, Masunaga K, Sugiyama $\mathrm{Y}$, et al. Non-neuronal cholinergic system in human bladder urothelium. Urology. 2006;67:425-430.

23 Kim JC, Park EY, Seo SI, Park YH, Hwang TK. Nerve growth factor and prostaglandins in the urine of female patients with overactive bladder. J Urol. 2006;175:1773-1776.

24 Kim DK, Thomas CA, Smith C, Chancellor MB. The case for bladder botulinum toxin application. Urol Clin North Am. 2006; 33:503-510.

25 Hawthorn MH. Chapple CR. Cock M. Chess-Williams R. Urothelium-derived inhibitory factor(s) influence detrusor muscle contractility in vitro. Br J Pharmacol. 2000;129:416-419.

26 Mansfield KJ, Liu L, Mitchelson FJ, Moore KH, Millard RJ, Burcher E. Muscarinic receptor subtype in human bladder detrusor and mucosa, studied by radioligand binding and quantitative competitive RT-PCR: changes in aging. $\mathrm{Br} \mathrm{J}$ Pharmacol. 2005;144:1089-1099.

27 Mukerji G, Yiangou Y, Grogono J, Underwood J, Agarwal SK, Khullar $\mathrm{V}$, et al. Localization of $\mathrm{M}_{2}$ and $\mathrm{M}_{3}$ muscarinic receptors in human bladder disorders and their clinical correlations. J Urol. 2006;176:367-373.

28 Yoshida M, Masunaga K, Nagata T, Maeda Y, Miyamoto Y, Kudoh J, et al. Attenuation of non-neuronal ATP release from human bladder mucosa by muscarinic agents. LUTS. 2009;2: 88-92.
29 de Groat WC, Downie JW, Levin RM, Long Lin AT, Morrison JFB, Nishizawa O, et al. Basic neurophysiology and neuropharmacology. In Abrams P, Khoury S, Wein A, editors. In: Incontinence, 1st International Consultation on Incontinence. Plymouth: Plymbridge Distributors Ltd.; 1999. p. 105-154.

30 Andersson K-E, Chapple CR, Cardozo L, Cruz H, Hashim H, Michel MC, et al. Pharmacological treatment of urinary incontinence. In: Abrams P, Cardozo L, Khoury S, Wein A, editors. Incontinence, 4th International Consultation on Incontinence. Plymouth: Health Publication Ltd.; 2009. p. 631-699.

31 Chapple C, Khullar V, Gabriel Z, Doolry JA. The effects of antimuscarinic treatments in overactive bladder: a systematic review and meta-analysis. Eur Urol. 2005;48:5-26.

32 Chapple CR, Patroneva A, Raines SR. Effect of an ATP sensitive potassium channel opener in subjects with overactive bladder: a randomized, double-blind, placebo-controlled study (ZD0947IL/0004). Eur Urol. 2006;49:879-886.

33 Massaro AM, Lenz KL. Aprepitant: a novel antiemetic for chemotherapy-induced nausea and vomiting. Ann Pharmacother. 2005;39:77-85.

34 Green SA, Alon A, Ianus J, McNaughton KS, Tozzi CA, Reiss TF. Efficacy and safety of a neurokinin-1 receptor antagonist in postmenopausal women with overactive bladder with urge urinary incontinence. J Urol. 2006;176:2535-2540.

35 Yamaguchi O, Chapple CR. Beta3-adrenoceptors in urinary bladder. Neurourol Urodyn. 2007;26:752-756.

36 Andersson KE, Arner A. Urinary bladder contraction and relaxation: physiology and pathophysiology. Physiol Rev. 2004;84: 935-986.

37 Michel MC, Vrydag W. Alpha1-, alpha2- and beta-adrenoceptors in the urinary bladder, urethra and prostate. Br J Pharmacol. 2006;147 Suppl 2:S88-S119.

38 Otsuka A, Shinbo H, Matsumoto R, Kurita Y, Ozono S. Expression and functional role of beta-adrenoceptors in the human urinary bladder urothelium. Naunyn Schmiedebergs Arch Pharmacol. 2008;377:473-481.

39 Nomiya M, Yamaguchi O. A quantitative analysis of mRNA expression of alpha 1 and beta-adrenoceptor subtypes and their functional roles in human normal and obstructed bladders. J Urol. 2003; 170:649-653.

40 Fujimura T, Tamura K, Tsutsumi T, Yamamoto T, Nakamura K, Koibuchi Y, et al. Expression and possible functional role of the beta3-adrenoceptor in human and rat detrusor muscle. J Urol. 1999;16:680-685.

41 Igawa Y, Yamazaki Y, Takeda H, Hayakawa K, Akahane M, Ajisawa $\mathrm{Y}$, et al. Functional and molecular biological evidence for a possible beta3-adrenoceptor in the human detrusor muscle. Br J Pharmacol. 1999;126:819-825.

42 Igawa Y, Yamazaki Y, Takeda H, Kaidoh K, Akahane M, Ajisawa $\mathrm{Y}$, et al. Relaxant effects of isoproterenol and selective beta3-adrenoceptor agonists on normal, low compliant and hyperreflexic human bladders. J Urol. 2001;165:240-244.

43 Takeda M, Obara K, Mizusawa T, Tomita Y, Arai K, Tsutsui T, et al. Evidence for beta3-adrenoceptor subtypes in relaxation of the human urinary bladder detrusor: analysis by molecular biological and pharmacological methods. J Pharmacol Exp Ther. 1999;288:1367-1373.

44 Morita T, Iizuka H, Iwata T, Kondo S. Function and distribution of beta3-adrenoceptors in rat, rabbit and human urinary bladder and external urethral sphincter. J Smooth Muscle Res. 
2000;36:21-32.

45 Biers SM, Reynard JM, Brading AF. The effects of a new selective beta3-adrenoceptor agonist (GW427353) on spontaneous activity and detrusor relaxation in human bladder. BJU Int. 2006;98:1310-1314.

46 Badawi JK, Seja T, Uecelehan H, Honeck P, Kwon ST, Bross S, et al. Relaxation of human detrusor muscle by selective beta-2 and beta-3 agonists and endogenous catecholamines. Urology. 2007;69:785-790.

47 Leon LA, Hoffman BE, Gardner SD, Laping NJ, Evans C, Lashinger ES, et al. Effects of the beta3-adrenergic receptor agonist disodium 5-[(2R)-2-[[(2R)-2-(3-chlorophenyl)-2-hydroxyethyl]amino]propyl]-1,3-benzodioxole-2,2-dicarboxylate (CL-316243) on bladder micturition reflex in spontaneously hy- pertensive rats. J Pharmacol Exp Ther. 2008;326:178-185.

48 Colli E, Digesu GA, Olivieri L. Overactive bladder treatments in early phase clinical trials. Expert Opin Investig Drugs. 2007;16:999-1007.

49 Cruz F, Dinis P. Resiniferatoxin and botulinum toxin type A for treatment of lower urinary tract symptoms. Neurourol Urodyn. 2007;26 6 Suppl:920-927.

50 Patel AK, Patterson JM, Chapple CR. Botulinum toxin injections for neurogenic and idiopathic detrusor overactivity: A critical analysis of results. Eur Urol. 2006;50:684-710.

51 Andersson K-E, Gratzke C. Bladder pharmacology and treatment of lower urinary tract: recent advances. UroToday Int J. 2008 Aug;1(2). doi:10.3834/uij.1939-4810.2008.07.06 